\section{Tsapko Y., Tsapko A. Bondarenko 0.}

\title{
RESEARCH OF THE MECHANISM OF PROTECTING WOOD WITH INTUMESCENT COATING
}

The object of research is intumescent coatings for wood, which, under the influence of high temperatures, are capable of forming a coked cellular material layer on the wood surf ace, which prevents the passage of temperature to the material. One of the most problematic areas in the application of these coatings is the unknown efficiency of the application and their performance characteristics. The effectiveness of wood fire protection in building structures and wood products is determined by the level of their ability to withstand thermal effects and is determined by the schedule of components under the influence of temperature with the absorption of heat and the formation of non-combustible gases. Thermal destruction of protected wood was carried out and volatile destruction products were identified, and a change in the components was obtained, namely, during thermal decomposition of fireprotected wood, the amount of combustible gases decreases and the amount of inert gases increases in the reverse order. To establish the effectiveness of wood protection with the given coating, it is necessary to conduct research on the wood flammability. In the course of the study, standardized equipment in accordance with DSTU 2289 was used. It was experimentally established that the treated wood is characterized by a low weight loss (2.2\%) and a flue gas temperature of less than $200^{\circ} \mathrm{C}$, and also belongs to hardly combustible materials. This is due to the fact that the coating, when exposed to high temperatures, forms a significant swelling coefficient and contributes to the formation of a heat-insulated coke layer, which prevents the wood from burning out, and the passage of high temperature to the material. Thanks to this, it is possible to obtain wood with indicators that do not spread a flame on the surface, and with a moderate smoke-forming ability. Compared with similar known inorganic-based coatings, characterized by low adhesion to wood with fluctuations in temperature and humidity, it provides such advantages as lower coating consumption and its weather resistance.

Keywords: protective agents, fire resistance of wood, volatile products, weight loss, surface treatment, protection efficiency.

\section{Introduction}

The cause of fires at objects where wood is used is the ignition of gaseous products of thermal and thermooxidative destruction (hydrogen, methane, carbon monoxide, etc.), which are formed in the process of high-temperature heating of building structures. The experience of using fire-resistant materials shows that the existing funds have low efficiency and environmental friendliness, and do not provide a sufficient level of protection against a complex of hazardous and harmful environmental factors, which necessitates the development of scientifically based approaches to their creation. When developing fire protection for wood, the leading role is played by the correct selection of substances in protective compositions, based on an objective and comprehensive study of their properties, as well as taking into account important aspects of fire hazard, such as flammability, flame spread over the surface, heat release, smoke-generating ability. The unsatisfactory effectiveness of protective equipment can be explained by insufficient knowledge of the mechanism of fire protection of wood, does not make obtaining objective information about the nature of the processes that occur during operation and about the result of exposure. At the same time, the problem of increasing the operational properties of fire-resistant materials in the case of using fire protection means on an inorganic basis remains unsolved today.

In recent years, from the proposed direction of research, there are known works aimed at creating fire retardants; in the process of heating, they form a coke heat-insulating layer on the surface of wood [1]. As an alternative solution to the problem of fire protection of wooden structures, it is possible to use protective compositions based on geocement, which are a type of alkaline cements. They are fire-, heat- and heat-resistant, as well as environmentally friendly and are characterized by increased durability due to the synthesis in their structure of substances, analogues of natural zeolites and feldspathoids [2]. They also have insignificant elasticity and, under the influence of the temperature factor, they emit only water vapor into the surrounding natural environment, but they require the application of a significant thickness of the protective layer to the building structure [3]. On the other hand, buoyant fire-retardant materials act on the principle of a significant decrease in the thermal conductivity of the coatings formed by them as a result of their transformation under intense heat exposure into coked cellular material layers, which are significantly pushed back in time at the moment of ignition 
of combustible structures made of wood [4]. For fire protection of building structures, special coatings and an organic basis of [5] are widely used, for example, chlorinated paraffins are used as an additive to polyolefin, which are well combined with polymer [6]. They are quite effective, but they can form efflorescence, increase their smoke-generating capacity and release toxic combustion products. A significant increase in the stability, density, and strength of the protective layer is achieved as a result of the directed formation of certain additives that form high-temperature compounds [7]. However, to confirm this process, the corresponding physicochemical calculations are not given. In addition, many coatings have a number of disadvantages, such as the effect of individual components, loss of functional properties with increasing ambient temperature [8]. This means that it is not determined how the process proceeds under temperature conditions in the range of the schedule of the fire retardant coating. Research has also been carried out on protective materials made from organic substances with a solution of colemanite ore [9]. It is shown that due to the established ratio, it becomes possible to adjust the content of components to ensure the process of heat resistance. The synergistic action of ammonium polyphosphate and aluminum oxide trihydrate as fire retardant components for an epoxy composition reinforced with natural fibers, as a fire retardant material, is given in [10]. It shows that warehouses were not always able to provide effective flame resistance when changing temperature. Therefore, the combustion process took place with an intense loss of mass, and to resolve this issue, the development of new approaches is required. Therefore, it is relevant to establish the effectiveness of fire protection for a long time of thermal exposure. At the same time, the unresolved component is to ensure the fire resistance of building structures, which made it necessary to conduct research in this direction.

Thus, the object of research was selected intumescent coatings for wood, capable of forming a coked cellular material layer on the wood surface under the influence of high temperature, which prevents the passage of temperature to the material. The aim of research is to determine the features of fire protection of wooden structures from the effects of high temperature with an intumescent coating.

\section{Methods of research}

Samples of pine wood were used to establish the flammability, flame spread and smoke formation of wood and the toxicity of combustion products. In order to compare the untreated and those that were treated (Fig. 1) with a fire-retardant intumescent coating based on organic and mineral substances «FIREWALL-WOOD» with a consumption of $260 \mathrm{~g} / \mathrm{m}^{2}$, an inorganic coating with a consumption of $420 \mathrm{~g} / \mathrm{m}^{2}$ [3].

The study of the mechanism of fire protection of wood with an intumescent coating was carried out in accordance with the method [3].

The qualitative and quantitative composition of these mixtures was determined by gas chromatography using a ЦВЕТ-500M gas chromatograph, manufactured by the research enterprise «Chromatograph», Ukraine.

Gas chromatography with a mass-selective detector equipped with an Autoingector 7683b autosampler: column HP-5 length $30 \mathrm{~m}$, ID $0.32 \mathrm{~mm}$, film $0.25 \mu \mathrm{m}$. Sample injection - auto, split 1:10 $(v=1 \mu \mathrm{kl}))$.

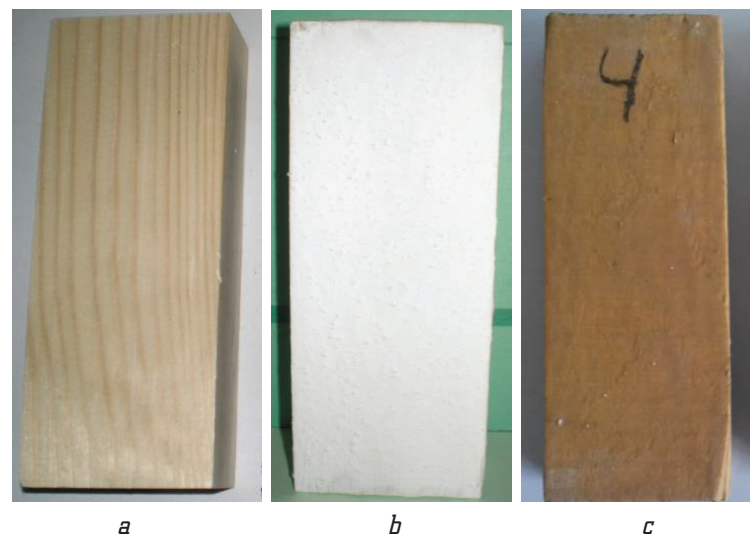

Fig. 1. Model samples of fire-resistant wood:

$a$ - untreated; $b$ - treated with a fire retardant intumescent coating $c$ - treated with geocement coating on an inorganic basis [3]

Pyrolysis is carried out in a tubular furnace when heated from $40{ }^{\circ} \mathrm{C}$ to $800^{\circ} \mathrm{C}$. The collection is carried out in a glass gas collector filled with a saturated solution of sodium chloride. For testing, prepare at least 5 samples weighing 100 g. Samples are conditioned in laboratory conditions, then weighed with an error of not more than $0.1 \mathrm{~g}$.

Studies to determine the group of flammability of wood, the index of flame spread and smoke generation, treated with the coating were carried out according to [3].

\section{Research results and discussion}

The effectiveness of fire protection of wood in building structures and wood products is determined by the level of their ability to withstand thermal effects. And first of all, it is caused by the schedule of components under the influence of temperature with heat absorption and the formation of non-combustible gases, a change in the process of thermal decomposition of materials in the direction of coke formation and inhibition of oxidation processes. On the other hand, the coating, when exposed to high temperatures, forms a significant swelling coefficient, contributes to the formation of a heat-insulating layer of coke, which prevents the wood from burning out and the passage of high temperature to the material. At the same time, the smoke-generating ability and combustion of the material is reduced. The composition of thermal destruction products depends on many conditions: the type of plant material, humidity, temperature, dynamics of air flow, and the like. A high content of combustible components - in gaseous products that are formed as a result of pyrolysis (thermal decomposition without air access). One of the methods that make it possible to study the formation of volatile products of fire-resistant wood is gas chromatographic analysis. The chromatographic analysis of volatile decomposition products of wood was carried out using the chromatograph «Tsvet-500M» (Fig. 2).

The results of gas chromatographic analysis of the resulting combustible mixtures are shown in Table 1.

It has been found that volatile destruction products differ significantly in the content of inert gases and the amount of combustible. For wood that was treated with an intumescent coating, an increase in inert gases, in particular $\mathrm{CO}_{2}$ by 1.46 times and nitrogen by 10.45 times, and a decrease in combustible gases were revealed. When treated with a geocement coating, it is mainly $\mathrm{CO}_{2}$ that increases. 


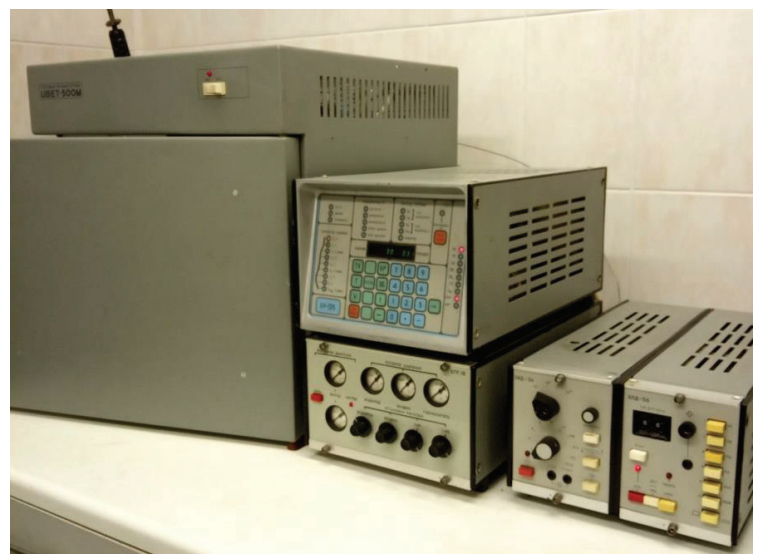

Fig. 2. Gas chromatograph «Tsvet-500M»

Tahle 1

Dualitative and quantitative composition of gaseous products of thermal destruction of wood

\begin{tabular}{|c|c|c|c|}
\hline \multirow{2}{*}{ Component } & \multicolumn{3}{|c|}{$\begin{array}{c}\text { Content of components in volatile products } \\
\text { of pine wood destruction, \% vol. }\end{array}$} \\
\cline { 2 - 4 } & $\begin{array}{c}\text { Not } \\
\text { treated }\end{array}$ & $\begin{array}{c}\text { Treated with } \\
\text { geocement coating }\end{array}$ & $\begin{array}{c}\text { Treated with } \\
\text { intumescent coating }\end{array}$ \\
\hline $\mathrm{CO}$ & 39.08 & 16.29 & 12.79 \\
\hline $\mathrm{CO}_{2}$ & 51.93 & 82.44 & 76.19 \\
\hline $\mathrm{CH}_{4}$ & 6.05 & 0.42 & 0.55 \\
\hline $\mathrm{C}_{2} \mathrm{H}_{6}+\mathrm{C}_{2} \mathrm{H}_{4}$ & 0.45 & 0.17 & Not found \\
\hline $\mathrm{C}_{3} \mathrm{H}_{8}$ & 0.19 & Not found & Not found \\
\hline $\mathrm{C}_{3} \mathrm{H}_{6}$ & 0.32 & Not found & Not found \\
\hline $\mathrm{H}_{2}$ & 0.73 & 0.52 & Not found \\
\hline $\mathrm{D}_{2}$ & 0.26 & Not found & Not found \\
\hline $\mathrm{N}_{2}$ & 0.99 & Not found & 10.45 \\
\hline
\end{tabular}

Considering that it is impossible to determine the group of fire-retardant efficiency of wood based on these studies, an experimental determination of the complex of fire-hazardous properties was carried out. Namely, flammability groups, flame spread index, smoke-generating ability.

The results of studies on determining the mass of samples $(\Delta m, \%)$ after combustion and an increase in the maximum temperature of gaseous combustion products $\left(\Delta t,{ }^{\circ} \mathrm{C}\right)$ are shown in Fig. 3, 4.

As seen from Fig. 3, 4, fire-retardant wood belongs to hardly combustible materials, since the temperature of gaseous combustion products did not exceed $189^{\circ} \mathrm{C}$, and the weight loss did not exceed $4.0 \%$ (Fig. 4). Samples treated with an intumescent coating (curve 3 ) with a weight loss of $2.1 \%$ and a flue gas temperature of less than $160{ }^{\circ} \mathrm{C}$ (Fig. 3) showed much greater efficiency.

To establish the ability to resist the spread of flame on the surface of the wood protected by the coating, appropriate studies were carried out (Fig. 5). For wood, the flame spread index was established on the basis of experimental data, which was 57.6 (Table 2). After that, tests were carried out on samples that were treated with coatings.

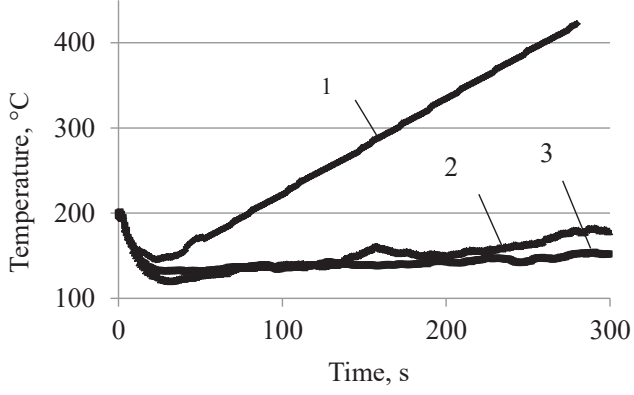

Fig. 3. Dynamics of the temperature rise of flue gases during testing of wood: 1 - untreated; 2 - treated with a coating on an

inorganic base; 3 - treated with intumescent coating

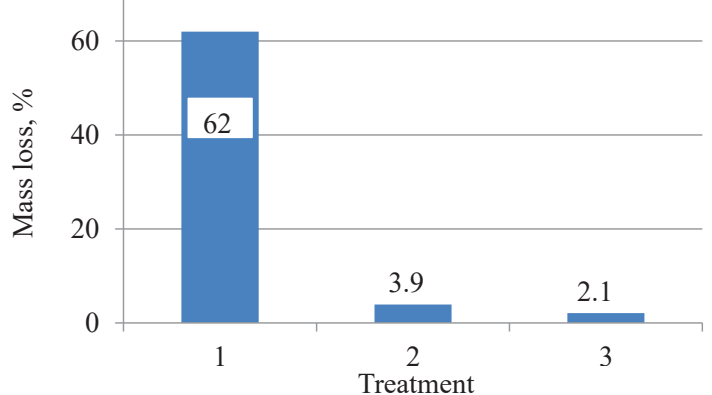

Fig. 4. Results of weight loss of samples $\Delta m, \%$ of fire-resistant wood 1 - untreated; 2 - treated with a coating on an inorganic base; 3 - treated with intumescent coating

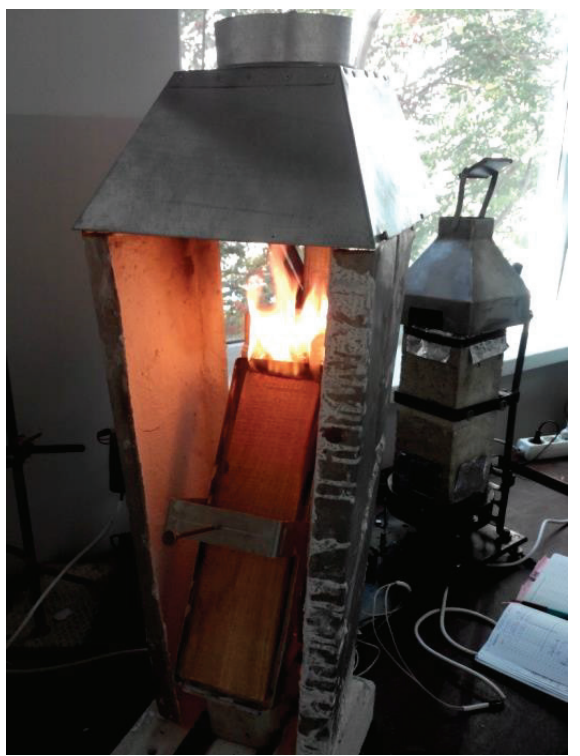

Fig. 5. Device for determining the index of flame spread over the wood surface

During tests on wood protected with a geocement coating, it was found that the sample caught fire for 181 seconds. The flame spread only to the first section, the maximum flue gas temperature was $105^{\circ} \mathrm{C}$ twice as long, and the flame spread index decreased about 12 times. No flame propagation occurred when using an intumescent coating.

The smoke generation of fire-resistant wood was determined, respectively, for each wood sample, namely, for untreated wood (1) and fire-resistant wood: intumescent coating (2) and coating on an inorganic basis (3), Table 3. 
The time the flame front passes through the points

\begin{tabular}{|c|c|c|c|c|c|c|c|c|c|c|c|c|c|c|c|}
\hline \multirow{2}{*}{ Wood sample } & \multicolumn{2}{|c|}{$\begin{array}{c}\text { Flue gas } \\
\text { temperature, }{ }^{\circ} \mathrm{C}\end{array}$} & \multicolumn{10}{|c|}{$\begin{array}{l}\text { The time the flame front passes through } \\
\text { the sample sections, } s\end{array}$} & \multirow{2}{*}{$\begin{array}{c}\text { Time to reach } \\
t_{\max ,} \mathrm{s}\end{array}$} & \multirow{2}{*}{$\begin{array}{l}\text { Sample damage } \\
\text { length } l_{g^{\prime}} \mathrm{mm}\end{array}$} & \multirow{2}{*}{$\begin{array}{c}\text { Flame spread } \\
\text { index }\end{array}$} \\
\hline & $t_{1}$ & $t_{\max }$ & 0 & 1 & 2 & 3 & 4 & 5 & 6 & 7 & 8 & 9 & & & \\
\hline Untreated & 89 & 355 & 20 & 26 & 8 & 21 & 55 & 39 & 30 & 51 & 91 & 30 & 122 & 300 & 57.6 \\
\hline Protected with geocement coating & 90 & 105 & 181 & - & - & - & - & - & - & - & - & - & 300 & 16 & 4.4 \\
\hline Protected with intumescent protected & 92 & 97 & - & - & - & - & - & - & - & - & - & - & 390 & 0 & 0 \\
\hline
\end{tabular}

Test results of the smoke production coefficient of wood

\begin{tabular}{|c|c|c|c|c|c|}
\hline \multirow{2}{*}{ Test mode } & \multirow{2}{*}{ No. of sample } & \multirow{2}{*}{ Sample mass $(m), \mathrm{kg} \cdot 10^{-3}$} & \multicolumn{2}{|c|}{ Light transmission, \% } & \multirow{2}{*}{ Smoke production coefficient $\left(D_{m}\right), \mathrm{m}^{2} / \mathrm{kg}$} \\
\hline & & & $\left(T_{0}\right)$ initial & $\left(T_{\min }\right)$ final & \\
\hline \multirow{3}{*}{$\begin{array}{l}\text { Flame combustion } \\
\left(35 \mathrm{~kW} / \mathrm{m}^{2}\right)\end{array}$} & 1 & 0.74 & 100 & 52 & 671.66 \\
\hline & 2 & 0.82 & 100 & 88 & 141.33 \\
\hline & 3 & 0.85 & 100 & 85 & 150.79 \\
\hline \multirow{3}{*}{$\begin{array}{l}\text { Smoldering } \\
\left(35 \mathrm{~kW} / \mathrm{m}^{2}\right)\end{array}$} & 1 & 0.79 & 100 & 48 & 766.32 \\
\hline & 2 & 0.84 & 100 & 72 & 300.98 \\
\hline & 3 & 0.87 & 100 & 76 & 290.33 \\
\hline
\end{tabular}

Note: 1 - untreated wood; fire-retardant wood; 2 - intumescent coating; 3 - geocement coating

The smoke production coefficient for wood in the smoldering mode is $766.32 \mathrm{~m} 2 / \mathrm{kg}$, which refers it to materials with a high smoke-generating ability. Fire protection reduces the smoke-generating ability by more than 2 times, and translates to materials with moderate smoke-forming ability.

Investigation of the mechanism of wood protection from the effects of high-temperature flame is a natural process of reducing the flammable volatile products of pyrolysis (Table 1). Under the influence of temperature, the formed volatile products of wood pyrolysis are characterized by the formation of inert components that inhibit active flame radicals. In addition, during the operation of the coating, a layer of coked cellular material is formed, which slows down the heat transfer processes. Protection by intumescent coatings, e. g. intumescent coatings, is characterized by the formation of a coke layer, which reduces the combustible components of the wood. This mechanism is a factor in regulating the degree of protection and the effectiveness of fire protection of wood. But, this can negatively affect the smoke-generating ability of the coating, since organic components are capable of increasing smoke production. That agrees with the data known from the works [4, 5], the authors of which agree to increase the smoke-forming ability. In contrast to the results of studies [6, 7], the data obtained on the thermal insulation of the foamed coke layer and changes in properties allow to state the following:

- the main regulator of the thermal insulation process is not only the formation of the coked cellular material layer, but also the formation of inert gases;

- a significant effect on the process of transition of a combustible material when using a fire retardant coating makes the transition to a group of hardly com- bustible materials that form a layer of pin coke on the surface, do not spread flame over the surface and are characterized by a low smoke-generating ability.

The transition of wood during the protection of the coating and the formation of an insulating layer of coke can't be solved within the framework of the above study, since additional experiments must be carried out in order to obtain more reliable data. In particular, the establishment of the point in time from which the drop in heat resistance begins, which will make it possible to investigate the coating surface, which moves towards an elevated temperature, and to determine those variables that affect the transformation of the coating into coke.

Further research will be aimed at studying the processes of establishing a connection between the nature of the components and such properties of coatings as the formation of foaming coke, as well as resistance to heat and weather.

\section{Conclusions}

The mechanism of wood protection by coatings during the formation of a heat-insulating coke layer has been investigated. Volatile degradation products has been revealed and a change in the components has been obtained, namely, during the thermal decomposition of a fire-resistant one, the amount of combustible gases decreases and the amount of inert gases increases in the reverse order.

It has been shown that the coating, when exposed to high temperatures, forms a significant swelling coefficient. This contributes to the formation of a heat-insulating layer of coke, which prevents the wood from burning out and 
the passage of high temperatures to the material, namely, with a weight loss of $2.1 \%$ and a flue gas temperature of less than $160{ }^{\circ} \mathrm{C}$. It has been established that wood products with fire protection belong to hardly combustible materials which slowly spread the flame and have a low smoke generating ability.

In the course of the study, data were obtained that allow to compare the coating for wood, to establish the processing costs. The research results will be useful for the design of building structures.

\section{References}

1. Tsapko, J., Tsapko, A. (2017). Simulation of the phase transformation front advancement during the swelling of fire retardant coatings. Eastern-European Journal of Enterprise Technologies, 2 (11 (86)), 50-55. doi: http://doi.org/10.15587/ 1729-4061.2017.73542

2. Krivenko, P. V., Guzii, S., Kravchenko, A. (2013). Protection of Timber from Combustion and Burning Using Alkaline Aluminosilicate-Based Coatings. Advanced Materials Research, 688, 3-9. doi: http://doi.org/10.4028/www.scientific.net/amr.688.3

3. Tsapko, Y., Tsapko, A. (2017). Establishment of the mechanism and fireproof efficiency of wood treated with an impregnating solution and coatings. Eastern-European Journal of Enterprise Technologies, 3 (10 (87)), 50-55. doi: http://doi.org/ 10.15587/1729-4061.2017.102393

4. Cirpici, B. K., Wang, Y. C., Rogers, B. (2016). Assessment of the thermal conductivity of intumescent coatings in fire. Fire Safety Journal, 81, 74-84. doi: http://doi.org/10.1016/ j.firesaf.2016.01.011

5. Fan, F., Xia, Z., Li, Q., Li, Z. (2013). Effects of inorganic fillers on the shear viscosity and fire retardant performance of waterborne intumescent coatings. Progress in Organic Coatings, 76 (5), 844-851. doi: http://doi.org/10.1016/j.porgcoat.2013.02.002

6. Xiao, N., Zheng, X., Song, S., Pu, J. (2014). Effects of Complex Flame Retardant on the Thermal Decomposition of Natural Fiber. BioResources, 9 (3), 4924-4933. doi: http://doi.org/10.15376/ biores.9.3.4924-4933
7. Carosio, F., Alongi, J. (2016). Ultra-Fast Layer-by-Layer Approach for Depositing Flame Retardant Coatings on Flexible PU Foams within Seconds. ACS Applied Materials \& Interfaces, 8 (10), 6315-6319. doi: http://doi.org/10.1021/acsami.6b00598

8. Md Nasir, K., Ramli Sulong, N. H., Johan, M. R., Afifi, A. M (2018). An investigation into waterborne intumescent coating with different fillers for steel application. Pigment $\mathcal{F}$ Resin Technology, 47 (2), 142-153. doi: http://doi.org/10.1108/prt09-2016-0089

9. Erdoǧan, Y. (2016). Production of an insulation material from carpet and boron wastes. Bulletin of the Mineral Research and Exploration, 152, 197-202. doi: http://doi.org/10.19111/ bmre.74700

10. Khalili, P., Tshai, K. Y., Hui, D., Kong, I. (2017). Synergistic of ammonium polyphosphate and alumina trihydrate as fire retardants for natural fiber reinforced epoxy composite. Composites Part B: Engineering, 114, 101-110. doi: http://doi.org/ 10.1016/j.compositesb.2017.01.049

Tsapko Yuriy, Doctor of Technical Sciences, Professor, Department of Technology and Design of Wood Products, National University of Life and Environmental Sciences of Ukraine, Kyiv, Ukraine; V. D. Glukhovsky Scientific Research Institute for Binders and Materials, Kyiv National University of Construction and Architecture, Ukraine, e-mail: juriyts@ukr.net, ORCID: http://orcid.org/ 0000-0003-0625-0783

Tsapko Oleksii, Postgraduate Student, Department of Technology and Design of Wood Products, National University of Life and Environmental Sciences of Ukraine, Kyiv, Ukraine, e-mail: alekseytsapko@gmail.com,ORCID: http://orcid.org/0000-00032298-068X

Bondarenko Olga, PhD, Associate Professor, Department of Building Materials, Kyiv National University of Construction and Architecture, Ukraine, e-mail: bondolya3@gmail.com, ORCID: http://orcid.org/ 0000-0002-8164-6473 